Revue Revue de l'histoire des religions

del'histoire des religions

4 | 2021

La magie entre Antiquité et Moyen Âge : traditions, innovations, autorités

Joseph YAcouB, Le Moyen-Orient syriaque. La face méconnue des chrétiens d'Orient

Paris, Éditions Salvator, 2019

Alain J. Desreumaux

\title{
OpenEdition
}

Journals

Édition électronique

URL : https://journals.openedition.org/rhr/11499

DOI : 10.4000/rhr.11499

ISSN : 2105-2573

Éditeur

Armand Colin

Édition imprimée

Date de publication : 1 décembre 2021

Pagination : 729-732

ISBN : 978-2-200-93378-4

ISSN : 0035-1423

Référence électronique

Alain J. Desreumaux, « Joseph YACouB, Le Moyen-Orient syriaque. La face méconnue des chrétiens

d'Orient », Revue de l'histoire des religions [En ligne], 4 | 2021, mis en ligne le 01 décembre 2021,

consulté le 06 janvier 2022. URL : http://journals.openedition.org/rhr/11499 ; DOI : https://doi.org/

$10.4000 /$ rhr. 11499

Ce document a été généré automatiquement le 6 janvier 2022

Tous droits réservés 


\section{Joseph YAcouB, Le Moyen-Orient syriaque. La face méconnue des chrétiens d'Orient}

Paris, Éditions Salvator, 2019

Alain J. Desreumaux

\section{RÉFÉRENCE}

Joseph YAcouB, Le Moyen-Orient syriaque. La face méconnue des chrétiens d'Orient, Paris, Éditions Salvator, 2019, 278 p., 21 cm, $20 €$, ISBN 978-2-7067-1832-8.

1 Le titre de l'ouvrage est à la fois injuste et justifié. Injuste car les communautés et les Églises syriaques font l'objet depuis le $\mathrm{XVI}^{\mathrm{e}}$ siècle au moins - l'auteur en parle lui-même, p.149-159-, de nombreuses études historiques, linguistiques, philologiques, théologiques, sociologiques dans de nombreuses institutions universitaires et académiques. Beaucoup de publications sont de haute qualité, mais l'auteur, qui cite souvent de grands savants du passé comme Ernest Renan, François Nau, George Badger, etc., ne dit mot des plus récentes recherches publiées, non seulement dans les grands corpus et les revues spécialisées, mais aussi dans des synthèses de remarquable vulgarisation comme par exemple les deux superbes volumes de Sebastian Brock \& David Taylor, The Hidden Pearl. The Syrian Orthodox Church and its Ancient Aramaic Heritage, Roma, Trans World Film Italia, 2001, et plus récemment le beau livre de Françoise Briquel Chatonnet et Muriel Debié, Le monde syriaque. Sur les routes d'un christianisme ignoré, Paris, Les Belles Lettres, 2017. Ce dernier pointe précisément du doigt l'absence de structures d'enseignement du syriaque et des cultures syriaques dans nos institutions où pourtant le grec, le latin, l'arabe, l'hébreu ont trouvé une place. Leurs auteures ont su dire, selon une heureuse formule (p.108), que la culture des savoirs syriaques, c'est une mémoire à la fois locale et universelle dont les porteurs ont contribué à notre Renaissance et à nos savoirs philologiques et théologiques. «La 
découverte par l'Europe des Pères syriaques" ne date donc pas du $\mathrm{xx}^{\mathrm{e}}$ siècle, contrairement à ce que dit J. Yacoub p. 26.

Il fallait, pour exprimer cela et en défendre la promotion auprès des universitaires et du grand public tant «latin » que «syriaque » lui-même, une rigueur philologique et historique qui fait défaut dans plusieurs chapitres de l'ouvrage, au détriment de ce qu'il devrait promouvoir. En effet, dans les pages du début, sur la langue, la terre, l'histoire ancienne, faute sans doute de prendre en considération les recherches historiques actuelles et même déjà anciennes sur l'Antiquité syro-mésopotamienne et les langues araméennes, l'ouvrage abonde en approximations, en équivoques, en amalgames et en erreurs. Parler de Chinois ouighour et de Chinois Ongüt (p.38) est équivoque et anachronique; donner comme étape du «Nouveau Réveil syriaque à partir du $\mathrm{xVI}^{\mathrm{e}}$ siècle » l'ouvrage - estimable sans conteste - d'Amédée Thierry sur Nestorius et Eutychès paru en 1879 montre un blocage entre la théologie syriaque et la grande crise autour de Nestorius qui concernait la totalité de l'empire et s'est déroulée d'abord en grec; on aimerait connaître exactement sur quels faits s'appuie l'auteur pour parler de « croisade littéraire menée par les Byzantins et les Latins contre les Syriaques jacobites et nestoriens, avec des autodafés de livres et la destruction de leurs fondamentaux " (p. 29) et en quoi consistent lesdits fondamentaux.

3 Considérons le chapitre "Quel sens donner au terme "Syriaque"?» (p. 45-49). L'accumulation (p. 45) des termes « assyriens, chaldéens, syriaques, assyro-chaldéens, syro-orientaux ou occidentaux » pour qualifier une même communauté issue de SyroMésopotamie ne manque pas d'étonner : c'est faire fi des importantes différences de cultures et de destins des diverses communautés et Églises syriaques au cours d'une longue et riche histoire. Il serait légitime au contraire de reprocher aux Occidentaux de les confondre : on aurait attendu de l'auteur d'en mettre en valeur la belle diversité qui s'est développée à partir de l'Édesse chrétienne du III $^{\mathrm{e}}$ siècle jusqu'en Asie et en Inde du Sud. On perçoit ainsi ce qui nous paraît comme un non-dit sous-jacent à son propos sur l'histoire de ceux qu'il appelle « les Syriaques » et qu'il fait remonter à un " peuple et [une] communauté historique d'Orient, héritière et continuatrice des Babyloniens, des Assyriens, des Chaldéens et des Araméens » (p.45-46); réduire le monde syriaque à " une même communauté issue de Syro-Mésopotamie » (p. 45) est une erreur ; celle-ci se révèle à plein dans les p.61-67 où l'auteur récupère sans sourciller les SyroMésopotamiens, Ahikar l'Assyrien, Gilgamesh, Hammourabi pour en faire "les ancêtres de Syriaques »: ne s'agirait-il pas pour lui de fournir des arguments historiques aux revendications nationalistes d'une soi-disant nation syriaque qui serait présente au moins mille ans av. J.-C. et que les événements auraient persécutée et empêché d'exister? Quel rêve cache l'expression "après la chute de leurs empires, ils [les Syriaques] ont réussi à fonder des royaumes et des principautés comme ceux d'Édesse, d'Adiabène et de Sindjar...»? Quels empires ? Édesse fut bien un royaume, avec une histoire qu'il conviendrait de ne pas réduire, mais l'auteur ne semble pas connaître le maitre ouvrage de J. B. Segal ni les nombreux articles sur les origines du christianisme en Osrhoène. Affirmer sans sourciller (p. 55-56) que "Ce royaume [...] fut le premier pouvoir politique chrétien dans les annales de l'humanité, partagé par les Syriaques et les Arméniens, depuis que le christianisme y devint religion d'État ", est totalement infondé. Passons sur l'existence du harranien (?) parmi les idiomes araméens (p. 18). Que signifie 
«le syriaque devint la langue graphique de nombreux peuples» (p.18)? La confusion entre langue et écriture atteint son comble p. 47 et 48 , où sont invoqués pêle-mêle alphabet, sous-alphabet (?), idiomes, graphies, euphonies, dialectes et sub-dialectes.

Plus grave, l'auteur contribue à propager des ressentiments infondés. Dire, p. 92, que "les Syriaques, sans distinction, furent condamnés comme hérétiques, considérés comme non fidèles à la vraie foi, celle de Byzance, et à ses normes et dogmes » n'a aucun sens historique. De même, son obstination à faire de Sévère d'Antioche un syriaque (p. 148) aurait bien étonné ce dernier! Que l'auteur n'ait pas su mettre en valeur le travail réalisé par Philoxène de Mabboug auprès de Sévère est étonnant. Quant aux imprécisions et erreurs chronologiques sur la Peshitta, elles ne contribuent pas à mettre en valeur l'extraordinaire bond culturel et théologique que représente ce chef-d'œuvre de la culture syriaque.

Il aurait fallu que l'auteur choisisse sa méthode et son projet pour éclairer ceux qu'il aime et qu'il veut valoriser dans leur héritage, soit militer pour une mémoire largement fantasmée, soit écrire l'histoire. Il fait cependant montre d'un certain travail d'historien dans la deuxième partie de son ouvrage et l'on se doit de lui en savoir gré malgré les critiques que suscitent ses erreurs historiques et linguistiques concernant l'Antiquité et les origines. En effet, son chapitre sur les Syriaques, les Arabes et l'islam (p. 101-117) donne des indications dont les actuelles communautés syriaques ainsi que les Occidentaux ont bien besoin. Sur les relations entre les Églises syriaques, le Vatican et les Églises réformées (p. 119-138), les points de repère et leur chronologie sont tout à fait intéressants et importants à connaître. Enfin les différents thèmes qui forment la dernière partie de l'ouvrage, p.149-260, constituent un survol nécessaire et une présentation de grands auteurs syriaques que beaucoup méconnaissent. Ils correspondent d'ailleurs aux thèmes systématiquement étudiés pour le monde francophone par la Société d'études syriaques, et pour le monde italien par l'association Syriaca. Ricerche siriache in Italia. L'ouvrage de Joseph Yacoub est une preuve de plus que l'on a bien besoin aujourd'hui de travailler à diffuser dans une vraie vulgarisation l'histoire et les richesses culturelles du monde syriaque.

De ce point de vue, toutes les erreurs et approximations tendancieuses sont dommageables. Dans le présent ouvrage, elles viennent de ce que celui-ci mélange constamment langues, écritures, graphies, cultures, religions, positions théologiques, provinces, empires, ethnies, nations, dans un amas où l'histoire et la linguistique ne sont pas respectées. Le sujet méritait un tout autre traitement, d'autant plus nécessaire en notre époque où les chrétiens d'Orient et particulièrement ceux des Églises syriaques vivent avec leurs compatriotes dans la douleur d'un Moyen-Orient dévasté. Il est juste d'affirmer que, malgré les nombreux travaux de qualité des philologues et des historiens - travaux que l'auteur reconnaît en parlant p. 48 d'« un renouveau sans précédent ", mais n'utilise guère - les chrétiens d'Orient restent méconnus tant de nombreux universitaires et de journalistes que du grand public. Les syriaques de l'Église d'Orient ont au premier chef besoin d'ouvrages pédagogiques clairs et solidement informés sur leur histoire et le patrimoine dont ils sont les vivants héritiers. Le présent ouvrage est malheureusement loin d'y contribuer. 


\section{AUTEURS}

\section{ALAIN J. DESREUMAUX}

Centre national de la recherche scientifique,

UMR « Orient \& Méditerranée », Paris. 